\title{
Polyhedral oligomeric silsesquioxane-based hybrid networks obtained via thiol-epoxy click chemistry
}

\author{
Seda Bekin Acar ${ }^{1} \cdot$ Mustafa Ozcelik $^{1} \cdot$ Tamer Uyar $^{2} \cdot$ Mehmet Atilla Tasdelen $^{1}$ (I)
}

Received: 18 December 2016 / Accepted: 25 April 2017 / Published online: 2 May 2017

(C) Iran Polymer and Petrochemical Institute 2017

\begin{abstract}
A series of hybrid networks based on polyhedral oligomeric silsesquioxane (POSS) were prepared by thiolepoxy click reaction using commercially available octakisglycidyl-POSS (G-POSS), trimethylolpropane triglycidyl ether, and trimethylolpropane tris(3-mercaptopropionate) as monomers. The click reaction was simply catalyzed by lithium hydroxide which proceeded readily at ambient conditions in very good yields. The incorporation of G-POSS into the network was clearly determined by transmission electron microscopy, FTIR, and ${ }^{1} \mathrm{H}-\mathrm{NMR}$ spectroscopy techniques performed with a model study using 1-butane thiol and G-POSS molecules. The homogeneous distribution of G-POSS up to $5 \mathrm{wt} \%$ in the hybrid network was apparently confirmed by morphological investigations. By increasing G-POSS content higher than $5 \mathrm{wt} \%$, the heterogeneous dispersion of G-POSS was determined from the tensile strength measurements. The significant decrease in tensile strength was possible due to the agglomeration of G-POSS. On the other hand, thermal properties of hybrid networks were compared together by thermogravimetric analyses, where all samples exhibited one-step degradation in the range of $220-500{ }^{\circ} \mathrm{C}$. The thermal decomposition of hybrid network led to complete degradation of the organic part and favored the formation of stable carbonaceous and inorganic residues as char. Thus, the char yields of hybrid networks were increased to $6.2,7.8,10.1,12.7$, and $15.1 \%$ by G-POSS loadings from 0 to $15 \mathrm{wt} \%$. This improvement
\end{abstract}

Mehmet Atilla Tasdelen

tasdelen@yalova.edu.tr

1 Department of Polymer Engineering, Faculty of Engineering, Yalova University, 77100 Yalova, Turkey

2 UNAM-Institute of Materials Science and Nanotechnology, Bilkent University, 06800 Ankara, Turkey was also a proof of the incorporation of G-POSS into the hybrid networks that resulted in high heat-resistant POSSbased hybrid networks compared to a sample without G-POSS.

Keyword Click chemistry $\cdot$ Hybrid networks $\cdot$ Polyhedral oligomeric silsesquioxanes · Thermosets · Thiol-epoxy reaction

\section{Introduction}

A combination of inorganic nanofillers and organic polymers may produce desirable properties in a single hybrid material [1]. Compatibility and miscibility of the initial components to control physical characteristics of final products are the most difficult problems in the production of hybrid materials [2]. Because of their hybrid structures, polyhedral oligomeric silsesquioxanes (POSS) are one of the most popular nanofillers having three dimensions ranging from 1 to $3 \mathrm{~nm}$ [3]. Hence, these molecules can be easily combined with almost all kinds of thermoplastics $[4,5]$ or thermosets [6-8] by blending, grafting, crosslinking, or copolymerization processes.

Click chemistry involves synthesis reactions developed to join two molecules rapidly in a single step without generating side products [9]. Due to their simplicity, these reactions can be found in a broad spectrum of applications such as bio-conjugation, radio-labeling of peptides, dendrimer and polymer synthesis, and modification of heterogeneous surfaces $[10,11]$. The coppercatalyzed azide-alkyne cycloaddition [12, 13], DielsAlder cycloaddition [14], oxime/hydrazone formation, and thiol-based [15] reactions have been adopted as click reactions in the literature [16-18]. Among them, 
thiol-based (e.g., thiol-ene, thiol-yne, thiol-epoxy, and thiol-Michael) click reactions [19] provide several advantages such as metal-free catalyst system, reasonable reaction times, using benign or no solvent, and requirement of simple purification techniques.

Because of its distinct characteristics regarding selectivity, controllability, fastness, and high efficiency, thiolepoxy reaction was considered as "click" chemistry reaction. Thiol-epoxy click reaction has been utilized in several applications [20] such as polymer synthesis [21, 22] and functionalization [23-25], hydrogel [26] and high-performance coatings [27-29], etc. [30, 31]. For example, linear polymers with reactive hydroxyl groups are easily prepared from commercially available 1,4-butanediol diglycidyl ether and 1,2 ethanedithiol monomers using lithium hydroxide as catalyst. The subsequent post-functionalization of this polymer allows a side-functional polymer to be obtained containing photoactive group [22].

In this study, polyhedral oligomeric silsesquioxane (POSS)-based hybrid networks were prepared by thiolepoxy click chemistry using commercially available multifunctional compounds, trimethylolpropane triglycidyl ether and trimethylolpropane tris(3-mercaptopropionate) as monomers and octakis-glycidyl-POSS (G-POSS) as a hybrid comonomer. The thiol-epoxy crosslinking polymerization was simply conducted under mild conditions (presence of oxygen and moisture at room temperature) using lithium hydroxide as catalyst. The influence of G-POSS concentration on the mechanical and thermal properties of the obtained hybrid networks was also investigated by transmission electron microscopy, thermogravimetric analysis, and a universal test machine. Besides, the incorporation of G-POSS into the network was also confirmed by FTIR and ${ }^{1} \mathrm{H}-\mathrm{NMR}$ spectroscopy techniques which was performed with a model study using 1-butanethiol and G-POSS molecules.

\section{Experimental}

\section{Materials}

Octakis-glycidyl-POSS (G-POSS, Hybrid Plastic, USA), trimethylolpropane triglycidyl ether (TTE, technical grade, Sigma-Aldrich, Germany), trimethylolpropane tris(3-mercaptopropionate) (TMPMP, $\geq 95.0 \%$, Sigma-Aldrich, Germany), 1-butanethiol (99\%, Sigma-Aldrich, Germany), and lithium hydroxide monohydrate $(\mathrm{LiOH}, 99.95 \%$, SigmaAldrich, Germany) were used as received. Dimethyl sulfoxide (99.9\%, Merck, Germany), tetrahydrofuran (99.9\%, Sigma-Aldrich, Germany), and deionized water were used as solvents.

\section{Analysis}

The Perkin-Elmer FTIR Spectrum One B spectrometer was used for FTIR analysis. The Agilent NMR System VNMRS 500 spectrometer was used at room temperature in $\mathrm{CDCl}_{3}$ with $\mathrm{Si}\left(\mathrm{CH}_{3}\right)_{4}$ as an internal standard for ${ }^{1} \mathrm{H}$ NMR analyses. The thermogravimetric analysis was conducted by Perkin-Elmer Diamond TA/TGA with a heating rate of $10{ }^{\circ} \mathrm{C} / \mathrm{min}$ under nitrogen flow $(200 \mathrm{~mL} / \mathrm{min})$. Transmission electron microscopy (TEM) observation was utilized by an FEI Tecnai ${ }^{\mathrm{TM}} \mathrm{G}^{2} \mathrm{~F} 30$ instrument operating at an acceleration voltage of $200 \mathrm{kV}$. Ultra-thin TEM specimens around $100 \mathrm{~nm}$ were cut by a cryo-ultramicrotome $\left(\mathrm{EMUC}_{6}+\mathrm{EMFC}_{6}\right.$, Leica) equipped with a diamond knife. Before TEM analyses, the obtained specimens were placed on porous carbon-coated grids. The tensile properties of samples were determined with a Zwick/Roell Z1.0 universal test machine at room temperature according to the DIN EN ISO 527-1 standard with a crosshead speed of $5 \mathrm{~mm} / \mathrm{min}$. For each sample, at least three specimens were tested to provide reproducibility.

\section{Preparation of POSS-based hybrid networks via thiol-epoxy click chemistry}

TMPMP (2.51 mmol, $1 \mathrm{~g})$ and TTE (2.51 mmol, $0.76 \mathrm{~g})$ with various G-POSS loadings $(0,2,5,10$ or $15 \%$ by weight $)$ in THF $(4.5 \mathrm{~mL})$ were stirred with a magnetic stirrer at room temperature. $\mathrm{LiOH}(0.55 \mathrm{mmol}, 23 \mathrm{mg})$ dissolved in distilled water $(0.5 \mathrm{~mL})$ was added into the resulting solution and the mixture was further stirred for a few minutes to obtain a completely homogeneous mixture. The solutions were poured into glass petri dishes and hybrid network structures were rapidly obtained after $5 \mathrm{~min}$ as a result of exothermic reactions. The samples were dried in a vacuum oven for $24 \mathrm{~h}$ at room temperature before the characterization.

\section{Results and discussion}

The combination of organic and inorganic components at nanoscale not only allows the construction of hybrid networks but also permits the coexistence of competing material properties (mechanical, thermal, optical, chemical resistance, permeability, density, etc.) in one material.

Typically, two different approaches can be used for the formation of hybrid materials: (1) well-defined preformed building blocks are reacted with each other to form a hybrid material in which the precursors still, at least partially, keep their original integrity and (2) one or both structural units are formed from the precursors that are transformed into a novel network structure [32]. 


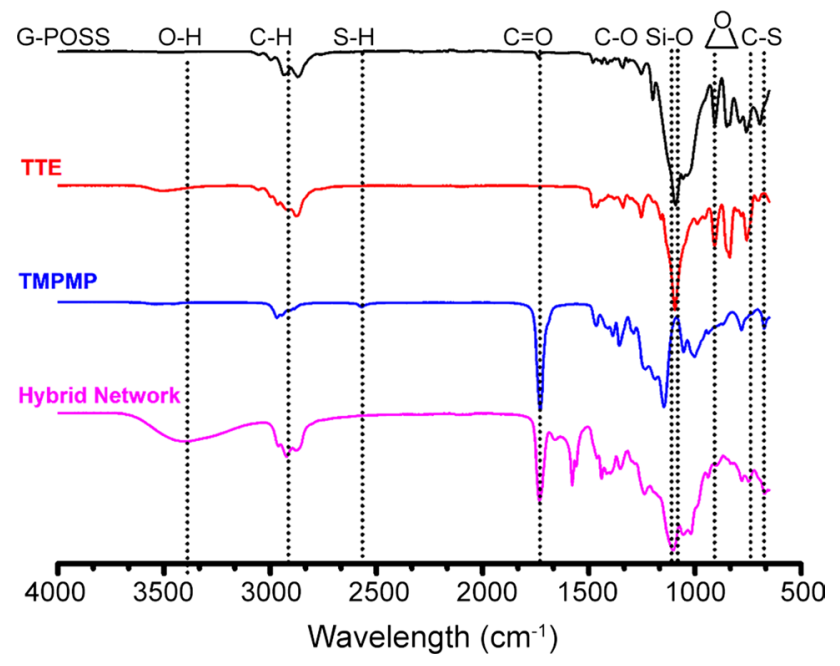

Fig. 1 Monitoring the formation of the hybrid network containing POSS molecules by FTIR spectroscopy

Due to their unique characteristics, the click chemistry reactions (such as CuAAC [33], Diels-Alder [14] and thiol-ene [34] reactions) were utilized for the preparation of organic-inorganic hybrid networks from appropriate nanoparticles (silica, metal, and POSS nanoparticles)
[35]. Recently, thiol-epoxy reaction has been considered as click reaction since this reaction fulfills most of the click chemistry criteria including a simple catalysis, solvent-free conditions, and proceeding rapidly to high yield even at room temperature [20]. To take advantage of these features, a series of hybrid networks containing $2,5,10$, and $15 \%$ G-POSS by weight were prepared by thiol-epoxy type click reaction using commercially available monomers, octakis-glycidyl-POSS, trimethylolpropane triglycidyl ether, and trimethylolpropane tris(3-mercaptopropionate). The $\mathrm{LiOH}$ was utilized as an efficient catalyst for the thiol-epoxy reactions at room temperature (Scheme 1).

The FTIR analysis was applied for the characterization of hybrid network formation along with initial compounds via thiol-epoxy click reaction. In the FTIR spectrum of hybrid networks, the characteristic epoxide bands of both G-POSS and TTE at $905 \mathrm{~cm}^{-1}$ disappeared completely, whereas a new peak at $3390 \mathrm{~cm}^{-1}$ assigned to $\mathrm{OH}$ group appeared distinctly (Fig. 1). In addition, the weak absorption band at $2570 \mathrm{~cm}^{-1}$ assigned to $\mathrm{SH}$ group of TMPMP was not detected after the thiol-epoxide reaction. On the other hand, the $\mathrm{C}-\mathrm{O}, \mathrm{Si}-\mathrm{O}, \mathrm{C}=\mathrm{O}$, and $\mathrm{C}-\mathrm{S}$ bands of initial compounds were evidently displayed at $1110,1080,740$, and $670 \mathrm{~cm}^{-1}$ in the FTIR spectrum
Scheme 1 Synthesis of POSSbased hybrid networks via thiolepoxy click chemistry
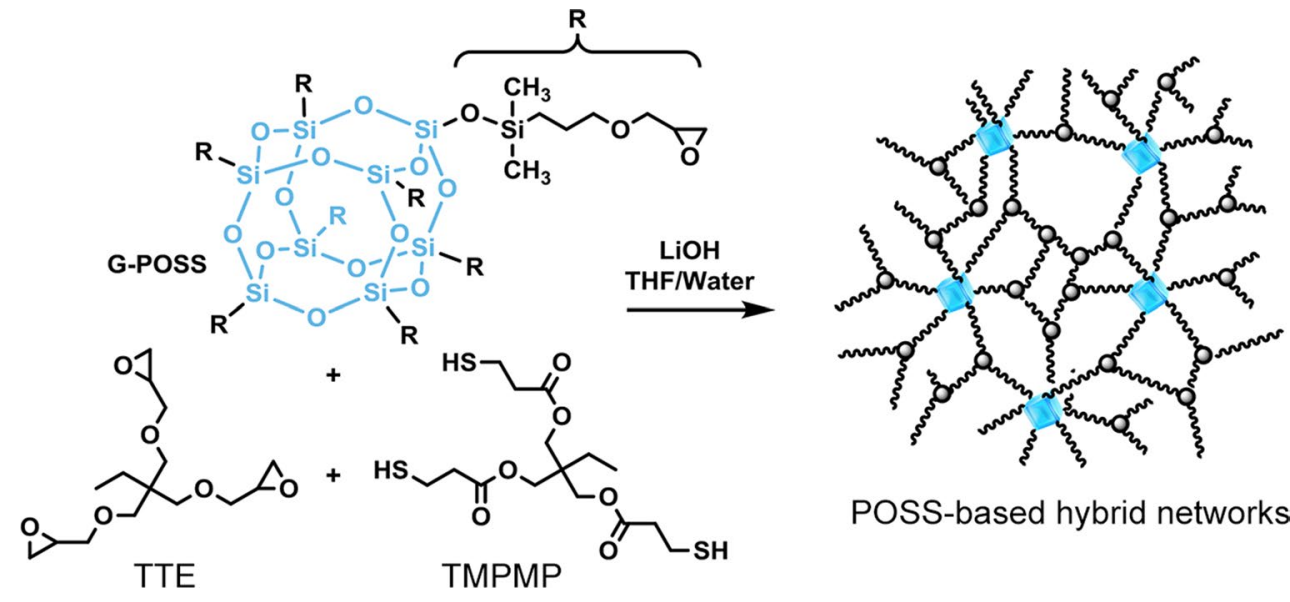

POSS-based hybrid networks
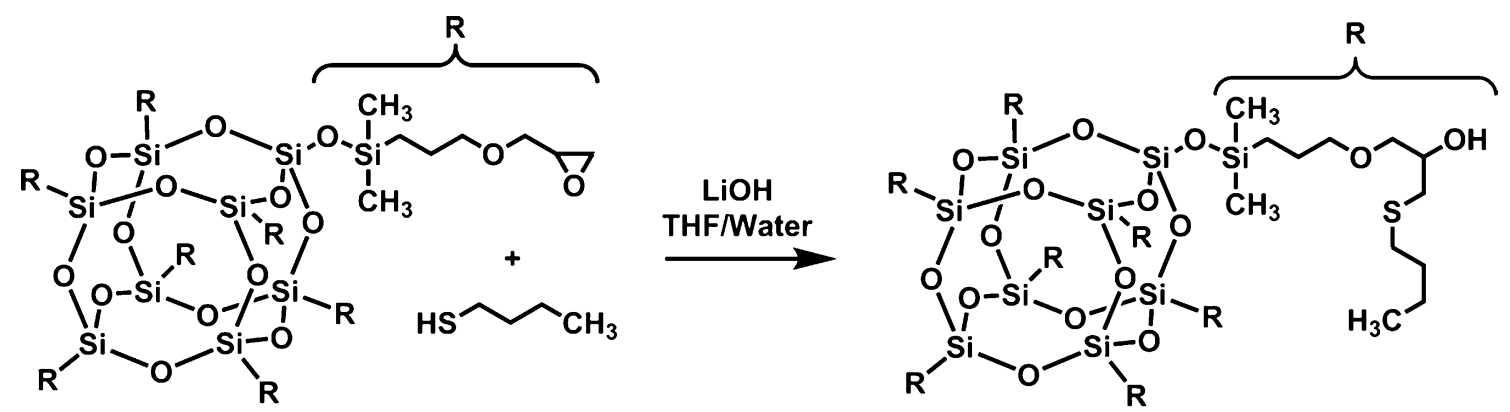

Scheme 2 Ring-opening reaction between G-POSS and 1-butane thiol via thiol-epoxy click reaction 


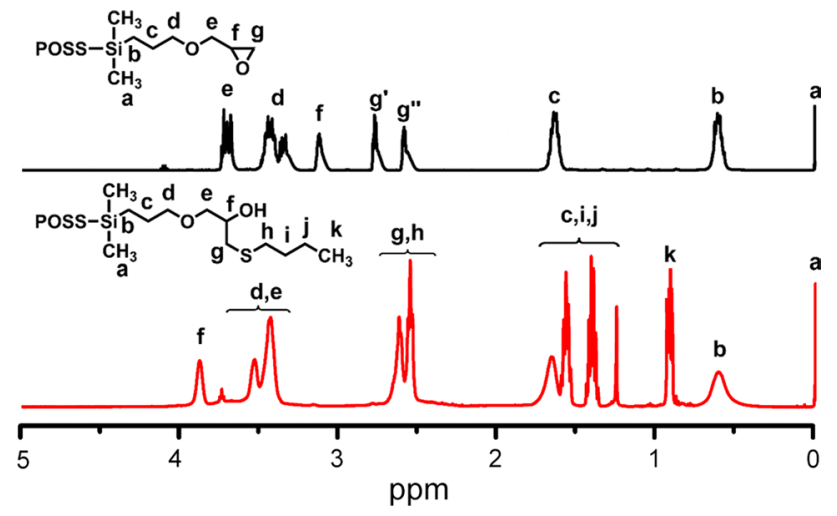

Fig. $2{ }^{1} \mathrm{H}-\mathrm{NMR}$ spectrum of the product obtained from the ringopening reaction between G-POSS and 1-butane thiol

of the hybrid network. As a result, the FTIR analysis of the product provided good assignment to the presence of G-POSS nanoparticles in the hybrid networks. The solubility tests using several solvents including acetone, acetonitrile, chloroform, diethyl ether, $N, N$-dimethylacetamide, dimethyl sulfoxide, 1,4- dioxane, $n$-hexane, methanol, tetrahydrofuran, and water were also carried out to confirm the highly crosslinked structures of hybrid networks. The results indicated that all samples were insoluble and there were no changes in the color of solutions.

To confirm the chemical bonding of POSS molecules in the network, the model study between G-POSS and 1-butane thiol under identical experimental condition was performed (Scheme 2) and the final product was characterized by ${ }^{1} \mathrm{H}-\mathrm{NMR}$ spectroscopy (Fig. 2). After the ring-opening reaction, the protons of epoxy ring (f) were completely shifted to higher frequency from 3.21 to $3.89 \mathrm{ppm}$, whereas methylene protons (e) next to epoxy ring were moved to lower frequency from 3.75 to 3.91 $4.12 \mathrm{ppm}$. In addition, new peaks belonging to methyl and methylene protons $(\mathbf{h}, \mathbf{i}, \mathbf{j}$, and $\mathbf{k})$ of 1-butane thiol appeared at $0.91,1.21-1.69$, and $3.91-4.12 \mathrm{ppm}$. All these findings undoubtedly confirmed that the G-POSS compound was chemically incorporated into the polymer matrix.

The morphological characterization of the hybrid network (HN-10) was carried out using transmission electron microscopy (TEM). According to the TEM micrograph with lower magnification, it was observed that a high concentration of G-POSS was homogenously distributed within the hybrid networks without apparent phase
Fig. 3 TEM micrographs of HN-5: a in low (scale bar $50 \mathrm{~nm}$ ); $\mathbf{b}$ in high (scale bar $20 \mathrm{~nm}$ ) magnifications; c energy-dispersive X-ray (EDX) spectrum
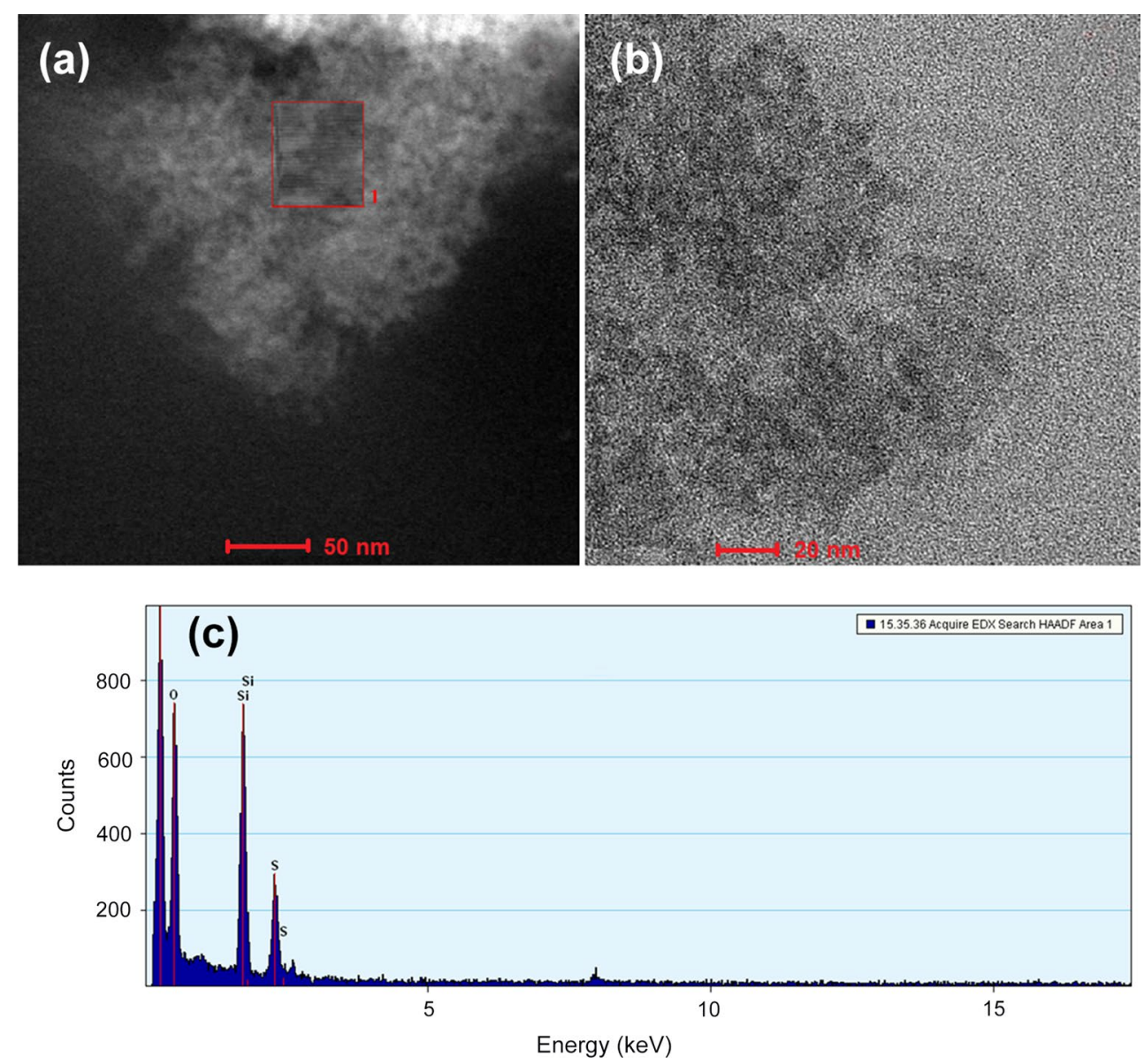


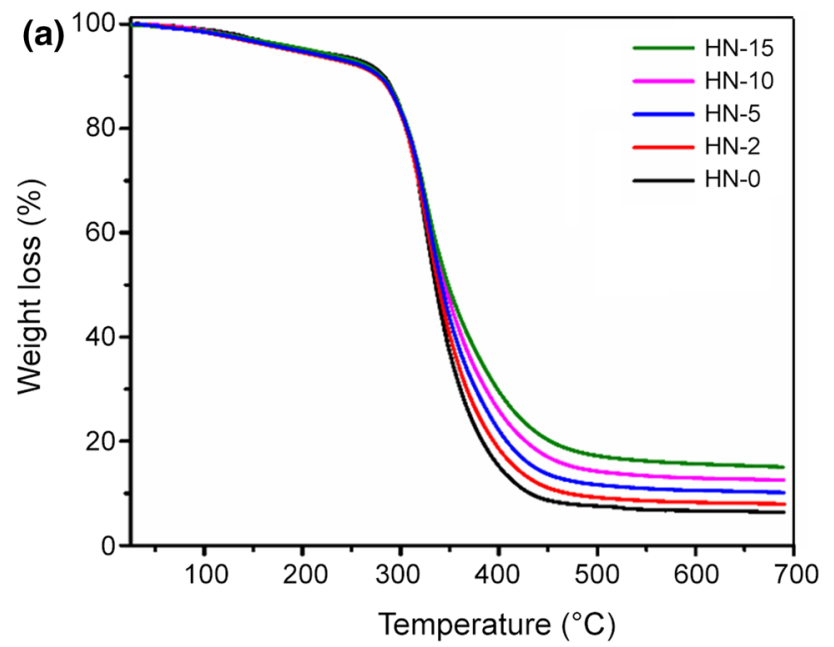

(b)

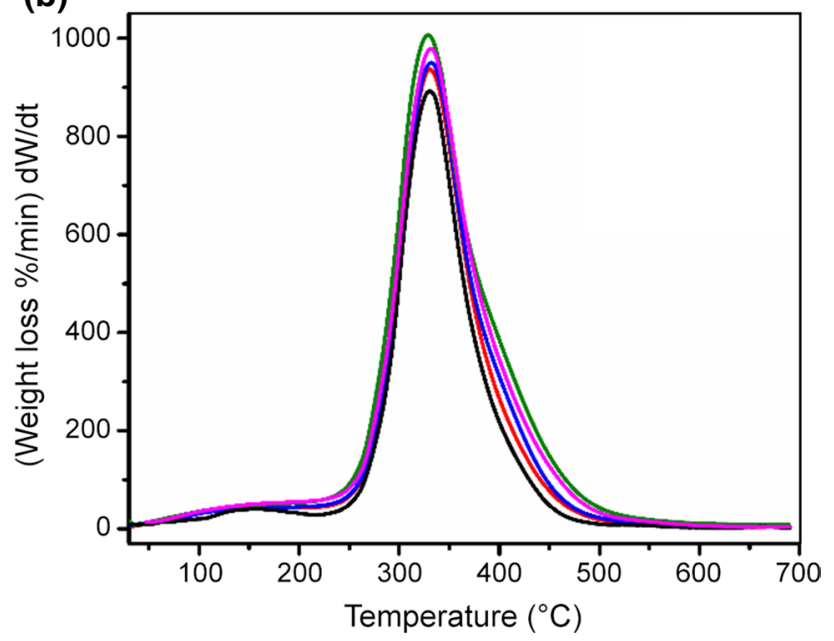

Fig. 4 TGA thermograms of hybrid networks containing G-POSS with various loadings $0,2,5,10$, and $15 \%$ of monomers by weight

separation. Furthermore, the TEM micrograph with higher magnification confirmed the size of G-POSS falls into the nanometer range of about $2-5 \mathrm{~mm}$. On the other hand, the energy-dispersive X-ray (EDX) detector mapping confirmed the existence of G-POSS as dark domains in the micrograph. Figure $3 \mathrm{c}$ displays the EDX image by energy release analysis arising from $\mathrm{C} \mathrm{K} \alpha, \mathrm{O} \mathrm{K} \alpha, \mathrm{Si} \mathrm{K} \alpha$, and $\mathrm{S}$ $\mathrm{K} \alpha$ elements at $0.28,0.53,1.72$, and $2.31 \mathrm{keV}$, respectively. These results undoubtedly confirm the presence of G-POSS molecules in the hybrid networks. Moreover, the ingredients of the hybrid networks were mainly ensued from C, O, $\mathrm{Si}$, and $\mathrm{S}$ elements.

Thermal stability of the hybrid networks was investigated by thermogravimetric (TGA) and difference thermogravimetric (DTG) analyses with a heating rate of $10^{\circ} \mathrm{C} /$ min in a nitrogen atmosphere (Fig. 4). All samples exhibited one-step degradation, which was attributed to the bond cleavages of $\mathrm{C}-\mathrm{O}-\mathrm{C}, \mathrm{C}-\mathrm{S}, \mathrm{C}-\mathrm{H}$, and $\mathrm{C}-\mathrm{C}$, in the range of

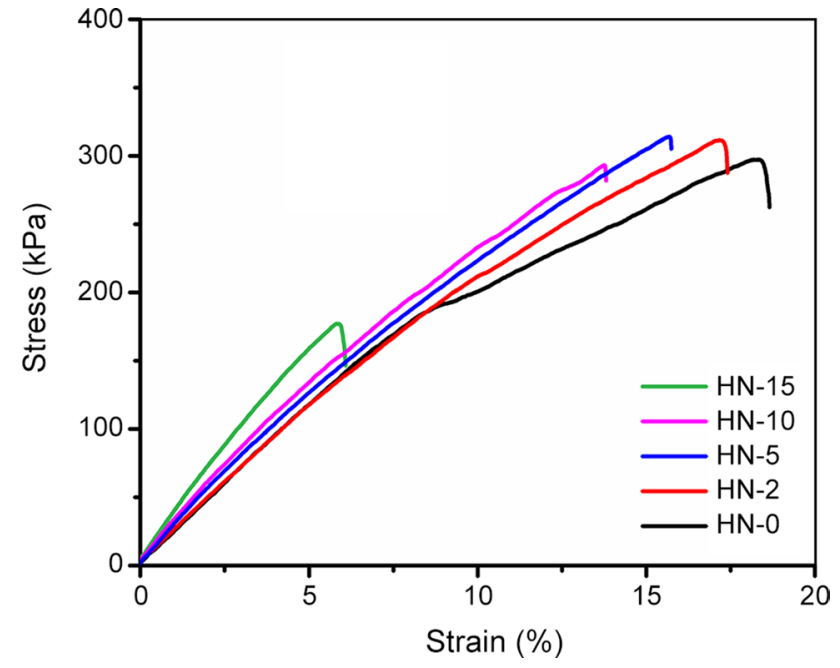

Fig. 5 Stress (\%)-strain ( $\mathrm{kPa})$ curves of G-POSS-containing hybrid networks

Table 1 Tensile strength (kPa), elongation-at-break (\%), and elastic modulus $(\mathrm{kPa})$ values of POSS-containing hybrid networks

\begin{tabular}{lllll}
\hline Sample & $\begin{array}{l}\text { POSS } \\
(\% \text { by wt })\end{array}$ & $\begin{array}{l}\text { Tensile } \\
\text { strength } \\
(\mathrm{kPa})\end{array}$ & $\begin{array}{l}\text { Elongation-at- } \\
\text { break } \\
(\%)\end{array}$ & $\begin{array}{l}\text { Elastic } \\
\text { modulus } \\
(\mathrm{kPa})\end{array}$ \\
\hline $\mathrm{HN}-0$ & 0 & 297.6 & 18.3 & 2590 \\
$\mathrm{HN}-2$ & 2 & 312.4 & 17.2 & 2790 \\
$\mathrm{HN}-5$ & 5 & 315.2 & 15.7 & 3370 \\
$\mathrm{HN}-10$ & 10 & 294.1 & 13.8 & 3490 \\
$\mathrm{HN}-15$ & 15 & 177.7 & 5.9 & 3580 \\
\hline
\end{tabular}

220-500 ${ }^{\circ} \mathrm{C}$. Moreover, these decompositions led to the complete degradation of the organic part of the hybrid networks and favored the formation of stable carbonaceous and inorganic residues as char. The char yields of hybrid networks were increased by G-POSS loadings according to $6.2,7.8,10.1,12.7$, and $15.1 \%$ for $\mathrm{HN}-0, \mathrm{HN}-2, \mathrm{HN}-5$, $\mathrm{HN}-10$, and HN-15, respectively. This improvement was also a proof of the incorporation of G-POSS into the hybrid networks that also provided high heat-resistant hybrid samples compared to neat sample in the absence of G-POSS. On the other hand, thermal decomposition behaviors of hybrid networks were completely similar with the result obtained from the neat sample in the absence of G-POSS.

The influence of G-POSS loading on the mechanical properties of hybrid networks was investigated by a universal tensile test machine. The amount of G-POSS in the polymer matrix played a very important role in determining the mechanical properties of final hybrid networks. From the stress-strain curves shown in Fig. 5, the addition of G-POSS up to $5 \%$ in the hybrid network made 
homogenous distribution as well as efficient interactions between G-POSS and matrix, and consequently, a remarkable enhancement in the tensile strength. By increasing the G-POSS content to 10 and $15 \%$ weight ratios, the tensile strength decreased by $\sim 1.2$ and $40.3 \%$ compared to neat sample (HN-0: $297.6 \mathrm{kPa})$. This result was also explained by previous studies, in which a large amount of POSS led to the agglomeration as well as its heterogeneous dispersion in the network. The tensile strength values of these hybrid networks significantly decreased due to the structural inhomogeneity. Also shown in Table 1, the increase of POSS weight percentage caused an increase in both rigidity and elastic modulus, but a decrease in elongation-at-break.

\section{Conclusion}

In conclusion, thiol-epoxy click reaction was reported as a versatile method for the preparation of POSS-based hybrid networks from commercially available monomers. The crosslinking process was conducted at ambient conditions (presence of oxygen and moisture at room temperature) using lithium hydroxide as catalyst. The presence of G-POSS in the network was clearly determined by both FTIR and TEM analyses. Moreover, the ${ }^{1} \mathrm{H}-\mathrm{NMR}$ result from the model study using G-POSS with 1-butane thiol as monofunctional thiol confirmed the successful thiol-epoxy click reaction. The incorporation of G-POSS improved the mechanical and thermal properties of POSS-based hybrid networks compared to the neat sample in the absence of G-POSS. By increasing G-POSS content higher than 5\%, the tensile strength significantly decreased due to the agglomeration and heterogeneous dispersion of G-POSS particles in the hybrid networks. This simple strategy will open new possibilities for the epoxy-based protective coatings where chemical stability, abrasion, and heat resistance are required.

\section{References}

1. Dawson R, Cooper AI, Adams DJ (2012) Nanoporous organic polymer networks. Prog Polym Sci 37:530-563

2. Liu S, Dicker KT, Jia X (2015) Modular and orthogonal synthesis of hybrid polymers and networks. Chem Commun 51:5218-5237

3. Kuo SW, Chang FC (2011) POSS related polymer nanocomposites. Prog Polym Sci 36:1649-1696

4. Doganci E, Tasdelen MA, Yilmaz F (2015) Synthesis of miktoarm star-shaped polymers with poss core via a combination of CuAAC click chemistry, atrp, and rop techniques. Macromol Chem Phys 216:1823-1830

5. Sencevik RG, Tasdelen MA (2014) Poly(methyl methacrylate)/ POSS hybrid networks by type II photoinitiated free radical polymerization. Polym Composite 35:1614-1620

6. Dizman C, Uyar T, Tasdelen MA, Yagci Y (2013) Synthesis and characterization of polysulfone/POSS hybrid networks by photoinduced crosslinking polymerization. Macromol Mater Eng 298:1117-1123

7. Arslan I, Tasdelen MA (2016) POSS-based hybrid thermosets via photoinduced copper-catalyzed azide-alkyne cycloaddition click chemistry. Des Monomers Polym 19:155-160

8. Hou G, Li N, Han H, Huo L, Gao J (2015) Hybrid cationic ring-opening polymerization of epoxy resin/glycidyloxypropyl-polyhedral oligomeric silsesquioxane nanocomposites and dynamic mechanical properties. Iran Polym J 24:299-307

9. Kolb HC, Finn MG, Sharpless KB (2001) Click chemistry: diverse chemical function from a few good reactions. Angew Chem Int Ed 40:2004-2021

10. Tasdelen MA, Yagci Y (2013) Light-induced click reactions. Angew Chem Int Ed 52:5930-5938

11. Tasdelen MA, Kiskan B, Yagci Y (2016) Externally stimulated click reactions for macromolecular syntheses. Prog Polym Sci 52:19-78

12. Rostovtsev VV, Green LG, Fokin VV, Sharpless KB (2002) A stepwise Huisgen cycloaddition process: copper(i)-catalyzed regioselective "ligation" of azides and terminal alkynes. Angew Chem Int Ed 41:2596-2599

13. Tornøe CW, Christensen C, Meldal M (2002) Peptidotriazoles on solid phase: [1-3]-triazoles by regiospecific copper(I)-catalyzed 1,3-dipolar cycloadditions of terminal alkynes to azides. J Org Chem 67:3057-3064

14. Tasdelen MA (2011) Diels-alder "click" reactions: recent applications in polymer and material science. Polym Chem 2:2133-2145

15. Lowe AB (2010) Thiol-ene "click" reactions and recent applications in polymer and materials synthesis. Polym Chem 1:17-36

16. Yagci Y, Tasdelen MA, Jockusch S (2014) Reduction of $\mathrm{Cu}$ (II) by photochemically generated phosphonyl radicals to generate $\mathrm{Cu}$ (I) as catalyst for atom transfer radical polymerization and azide-alkyne cycloaddition click reactions. Polymer 55:3468-3474

17. Tinmaz HB, Arslan I, Tasdelen MA (2015) Star polymers by photoinduced copper-catalyzed azide-alkyne cycloaddition click chemistry. J Polym Sci A Polym Chem 53:1687-1695

18. Demirci G, Tasdelen MA (2015) Synthesis and characterization of graft copolymers by photoinduced cuaac click chemistry. Eur Polym J 66:282-289

19. Jiang L, Peng Z, Guo A, Ye L, Feng ZG (2015) A one-step synthesis of polyrotaxane via in situ michael addition reaction. Iran Polym J 24:679-685

20. Stuparu MC, Khan A (2016) Thiol-epoxy "click" chemistry: application in preparation and postpolymerization modification of polymers. J Polym Sci A Polym Chem 54:3057-3070

21. De S, Khan A (2012) Efficient synthesis of multifunctional polymers via thiol-epoxy "click" chemistry. Chem Commun 48:3130-3132

22. Binder S, Gadwal I, Bielmann A, Khan A (2014) Thiol-epoxy polymerization via an $\mathrm{AB}$ monomer: synthetic access to high molecular weight poly(beta-hydroxythio-ether)s. J Polym Sci A Polym Chem 52:2040-2046

23. Brandle A, Khan A (2012) Thiol-epoxy 'click' polymerization: efficient construction of reactive and functional polymers. Polym Chem 3:3224-3227

24. Gadwal I, Khan A (2013) Protecting-group-free synthesis of chain-end multifunctional polymers by combining atrp with thiol-epoxy 'click' chemistry. Polym Chem 4:2440-2444

25. Acebo C, Fernandez-Francos X, Ramis X, Serra A (2016) Multifunctional allyl-terminated hyperbranched poly(ethyleneimine) as component of new thiol-ene/thiolepoxy materials. React Funct Polym 99:17-25 
26. Cengiz N, Rao JY, Sanyal A, Khan A (2013) Designing functionalizable hydrogels through thiol-epoxy coupling chemistry. Chem Commun 49:11191-11193

27. Fernandez-Francos X, Konuray AO, Belmonte A, De la Flor S, Serra A, Ramis X (2016) Sequential curing of off-stoichiometric thiol-epoxy thermosets with a custom-tailored structure. Polym Chem 7:2280-2290

28. Guzman D, Ramis X, Fernandez-Francos X, Serra A (2015) Preparation of click thiol-ene/thiol-epoxy thermosets by controlled photo/thermal dual curing sequence. RSC Adv 5:101623-101633

29. Guzman D, Ramis X, Fernandez-Francos X, Serra A (2014) New catalysts for diglycidyl ether of bisphenol a curing based on thiol-epoxy click reaction. Eur Polym J 59:377-386

30. Guzman D, Ramis X, Fernandez-Francos X, Serra A (2015) Enhancement in the glass transition temperature in latent thiolepoxy click cured thermosets. Polymers 7:680-694
31. Acebo C, Fernandez-Francos X, Ramis X, Serra A (2016) Thiolyne/thiol-epoxy hybrid crosslinked materials based on propargyl modified hyperbranched poly(ethyleneimine) and diglycidylether of bisphenol a resins. RSC Adv 6:61576-61584

32. Kickelbick G (2003) Concepts for the incorporation of inorganic building blocks into organic polymers on a nanoscale. Prog Polym Sci 28:83-114

33. Binder WH, Sachsenhofer R (2007) 'Click' chemistry in polymer and materials science. Macromol Rapid Commun 28:15-54

34. Hoyle CE, Bowman CN (2010) Thiol-ene click chemistry. Angew Chem Int Ed 49:1540-1573

35. Sumerlin BS, Vogt AP (2010) Macromolecular engineering through click chemistry and other efficient transformations. Macromolecules 43:1-13 